\title{
Counterconditioning During Reconsolidation Prevents Relapse of Cocaine Memories
}

\author{
Koral Goltseker', Lilach Bolotin' and Segev Barak*,1,2 \\ 'School of Psychological Sciences, Tel Aviv, Israel; '2Sagol School of Neuroscience, Tel Aviv University, Tel Aviv, Israel
}

Relapse to drug abuse is often caused by exposure to drug-associated cues that evoke craving. Therefore, disruption of the cue-drug memory can prevent relapse. Memories destabilize and become temporarily labile upon their retrieval, and re-stabilize in a process termed reconsolidation. Pharmacological disruption of reconsolidation prevents relapse in animal models, yet may evoke side effects. Therefore, behavioral procedures capable of preventing cue-induced craving and relapse are extremely valuable. Aversion therapies, in which drugpaired cues are re-associated (counterconditioned) with aversive consequences, have limited success, because the previous cue-drug memory may recover, triggering relapse. Here, we prevented the memory recovery and relapse to cocaine seeking by applying aversive counterconditioning during memory reconsolidation. Mice were trained to seek cocaine in a conditioned place preference procedure. The cocaine-associated compartment was then counterconditioned with lithium chloride (LiCl)-induced malaise, preceded by a brief exposure to the compartment (memory retrieval). Relapse was assessed in a reinstatement test. We found that aversive counterconditioning conducted shortly after memory retrieval (during reconsolidation) induced a long-lasting prevention of relapse to cocaine seeking. However, mice relapsed when counterconditioned without, before, or long after memory retrieval, or when receiving LiCl without place counterconditioning. Our findings suggest that post-retrieval aversive counterconditioning leads to relapse prevention, possibly by replacing the cue-drug with a cue-aversion memory, thereby the cue ceases to evoke craving. Moreover, we found that a similar memory replacement procedure prevented relapse of conditioned place aversion. Hence, this novel procedure can also prevent relapse of aversive memories, providing a safe approach to alter various maladaptive behaviors.

Neuropsychopharmacology (2017) 42, 716-726; doi:I0.1038/npp.2016.140; published online 31 August 2016

\section{INTRODUCTION}

Drug addiction has been extensively described as a disorder of learning and memory (Stewart et al, 1984; Wise, 1987; Hyman, 2005; Milton and Everitt, 2012). In addicts, the reinforcing effects of the drug become strongly associated with environmental cues and objects used for drug consumption during repeated drug intake (Hyman et al, 2006; O'Brien et al, 1992; Wikler, 1973). Consequently, the mere exposure to drug-paired cues elicits strong craving and relapse even after protracted abstinence (O'Brien et al, 1992). Therefore, disruption of the cue-drug association is expected to reduce or prevent cue-induced relapse.

Aversion therapies have been used to attenuate relapse of persistent unwanted memories such as cue-induced drug craving (Cannon et al, 1981; Frawley and Smith, 1990). In this therapeutic approach, a cue, previously associated with the reinforcing effects of a drug, is re-associated (counterconditioned) with an aversive outcome, such as a mild electrical shock or induction of nausea (Cannon et al, 1981; Frawley and

* Correspondence: Dr S Barak, School of Psychological Sciences, The Sagol School of Neuroscience, Tel Aviv University, Tel Aviv 69978, Israel, Tel: +972 3 6408969, Fax: +972 36409547

E-mail: barakseg@post.tau.ac.il

Received 23 March 2016; revised 19 July 2016; accepted 25 July 20 I6; accepted article preview online 29 July 2016
Smith, 1990). Aversive counterconditioning was shown to be more potent than extinction in suppressing relapse in animal models and humans (Van Gucht et al, 2010; Tunstall et al, 2012). However, this suppressive effect is temporary, and aversion therapies have limited success across time, since the cue-drug association can later recover, leading to cue-induced craving and relapse. This recovery of the original memory suggests that aversive counterconditioning leads to the formation of a new cue-aversion association that competes with the cue-drug associative memory trace for behavioral expression (Bouton and Peck, 1992; Brooks et al, 1995), rather than changing or disrupting the cue-drug memory.

In recent years an alternative approach for memory disruption has been suggested, via interference with memory reconsolidation (Nader and Hardt, 2009). Specifically, it is increasingly accepted that memories destabilize upon their retrieval, after which they re-stabilize in order to persist, in a process of reconsolidation (Nader and Hardt, 2009; Dudai, 2012; Merlo et al, 2015). Therefore, the retrieved memory becomes labile for a short period of time termed the 'reconsolidation window', during which it can be strengthened, updated, or even erased (Nader and Hardt, 2009; Dudai, 2012; Reichelt and Lee, 2013; Tronson and Taylor, 2013). Reconsolidation of drug-associated memories is disrupted by inhibition of protein synthesis in animal models, resulting in a reduced cue-induced reinstatement 
of drug-seeking behavior (eg, von der Goltz et al, 2009; Barak et al, 2013; Tronson and Taylor, 2013). However, most pharmacological treatments used to disrupt memory reconsolidation may cause serious side effects. Thus, behavioral procedures capable of disrupting drug memory reconsolidation and preventing cue-induced craving and relapse are of extreme translational value.

Here, we sought to prevent the recovery of the cue-drug memory and the consequent cue-induced craving and relapse by replacing the cue-drug with a cue-aversion memory. Specifically, we tested whether aversive place counterconditioning, conducted within the 'reconsolidation window', can prevent relapse of cocaine-conditioned place preference (CPP) in mice.

\section{MATERIALS AND METHODS}

For a detailed description of materials and apparatus, see Supplementary Information.

\section{Animals}

C57BL/6J mice (bred at Tel-Aviv University Animal Facility, Israel; 25-30 g) were housed 3-4/cage and kept under a 12-h light-dark cycle (lights on at 0400 hours) with food and water available ad libitum. All experimental protocols were conformed to the guidelines of the Institutional Animal Care and Use Committee of Tel Aviv University, Tel Aviv, Israel. All efforts were made to minimize the number of animals used.

\section{Place Conditioning, Counterconditioning and Reinstatement}

All mice were habituated to daily i.p. saline administrations 5 days prior to the beginning of the procedure, which was conducted in a two-compartment unbiased CPP apparatus (see Supplementary Information). The compartments differed in wall patterns and floor texture, and were divided by a sliding door.

Baseline Test (day 1). On the first day, the sliding door was retracted and mice were allowed to explore the entire apparatus freely for $30 \mathrm{~min}$. Animals that spent $>70 \%$ of time in either of the compartments were excluded from the study (one mouse from Experiments $3 a$ and 4). This allowed the use of an unbiased design, in which the two compartments are (a) equally preferred before conditioning as indicated by the group average (unbiased apparatus); (b) pseudo-randomly assigned to the experimental conditions (unbiased assignment procedure) (Mucha et al, 1982).

Conditioning (days 2-7 in Experiments 1-3; days 2-9 in Experiment 4). Training started $24 \mathrm{~h}$ after the Baseline Test with one session per day over 6 or 8 days, with the sliding door closed. On days 3, 5, 7 (and 9 in Experiment 4) mice were administered with cocaine ( $15 \mathrm{mg} / \mathrm{kg}$; i.p.) and immediately confined to the paired compartment for 30 min (Experiments 1-3), or were administered with $\mathrm{LiCl}$ (150 mg/kg; i.p.) and then confined to the paired compartment for $45 \mathrm{~min}$ (Experiment 4). On the alternate days (days
2, 4, 6, and also 8 in Experiment 4), mice were administered with vehicle and were confined to the unpaired compartment for the same duration as on the drug-conditioning day. Paired compartments were counterbalanced.

Place Preference Test 1 (day 8 in Experiments 1-3, day 10 in Experiment 4). Place preference test was identical to the Baseline Test. In Experiments 1-3 this test served to index cocaine-CPP (Mucha et al, 1982; Itzhak and Martin, 2002; Cunningham et al, 2006), and in Experiment 4 it served to index LiCl-conditioned place aversion (CPA) (Martin and Itzhak, 2000; Parker and Mcdonald, 2000; Legastelois et al, 2015). Preference or avoidance was defined as an increase or a decrease, respectively, in the percent of time spent in the drug-paired compartment on the Place Preference Test 1, compared with the Baseline Test.

Counterconditioning, coupled or not coupled with memory retrieval (days 9-16 in Experiments 1a and 3; days 9-12 in Experiment $1 b$; days 11-16 in Experiment 4). Training began $24 \mathrm{~h}$ after Place Preference Test 1, with a session per day over 8 days (4 days in Experiment 1b; 6 days in Experiment 4), similar to the Conditioning stage. Specifically, on the paired days mice from the Retrieval group were confined to the paired compartment for $4 \mathrm{~min}$ in order to retrieve the drug-associated memories (thus initiating the memory reconsolidation process). Mice from the control, No Retrieval group were handled. Mice were then returned to their home cages and held in a service room adjoined to the experiment room. Counterconditioning was conducted after (Experiments 1, 3a, 4) or before (Experiment 3b) the memory retrieval. For aversive counterconditioning training, mice were administered with $\mathrm{LiCl}$ (Experiments 1 and 3) and were immediately confined to the paired compartment for $45 \mathrm{~min}$ (Retrieval group) or $49 \mathrm{~min}$ (control, No Retrieval group). In Experiment 4, the Retrieval and No Retrieval groups were administered with cocaine and confined to the compartment for 26 and $30 \mathrm{~min}$, respectively. See more details in the Experimental Designs section.

Place Preference Test 2 (day 17; day 13 in Experiment 1b). This stage was identical to the previous test stages, and confirmed that counterconditioning led to loss of cocaineCPP (Experiments 1 and 3) or LiCl-CPA (Experiment 4).

Reinstatement (relapse) Test (day 18; days 26 and 40 in Experiment 1b). On this day, all mice received a prime administration, half of the conditioning dose (Mueller and Stewart, 2000) of cocaine $(7.5 \mathrm{mg} / \mathrm{kg}$, Experiments $1-3)$ or $\mathrm{LiCl}(75 \mathrm{mg} / \mathrm{kg}$, Experiment 4) immediately before a $30-\mathrm{min}$ test session with free access to both compartments. This test is considered to model relapse to cocaine seeking (Mueller and Stewart, 2000; Itzhak and Martin, 2002). A pilot experiment indicated that cocaine-prime administration, but not saline-prime administration, reinstates cocaine-CPP $48 \mathrm{~h}$ after aversive counterconditioning (Supplementary Figure S1). Relapse to cocaine-CPP was defined as an increase in the percentage of time spent in the drug-paired compartment during the Reinstatement Test, as compared with the Place Preference Test 2 (Experiments 1-3). In Experiment 4 , a decrease in the percentage of time spent in 
the drug-paired compartment indicated reinstatement of avoidance from the LiCl-associated compartment (Parker and Mcdonald, 2000).

\section{Experimental Designs}

Experiment 1a. After completing a Baseline Test, mice underwent cocaine-place conditioning, and expression of CPP was confirmed by Place Preference Test 1 . Mice were then divided into two groups: a Retrieval group, which underwent memory retrieval, and a control, No Retrieval group, which received handling. One hour later, all mice underwent counterconditioning with $\mathrm{LiCl}$, and abolition of cocaine-CPP was confirmed by Place Preference Test 2 on the following day. The next day, all mice underwent a Reinstatement Test.

Experiment $1 b$. This experiment was similar to Experiment 1a, except that mice underwent a Reinstatement Test 14 and 28 days after the last place counterconditioning session (which translates to 19 and 33 days after the last cocaine-conditioning session).

Experiment 2. This experiment was similar to Experiment $1 \mathrm{a}$, except that in the second phase, mice were not placed in the apparatus after $\mathrm{LiCl} /$ vehicle administration, but were instead returned to their home cages.

Experiment 3a. This experiment was similar to Experiment $1 \mathrm{a}$, except that the counterconditioning sessions were conducted $5 \mathrm{~h}$ after the memory retrieval session.

Experiment $3 b$. This experiment was similar to Experiment $1 \mathrm{a}$, except that the counterconditioning sessions were conducted $1 \mathrm{~h}$ before (rather than after) the memory retrieval session.

Experiment 4. This experiment was similar to Experiment $1 \mathrm{a}$, except that mice first underwent LiCl-place conditioning, and during the second phase of the experiment received place counterconditioning with cocaine $1 \mathrm{~h}$ after memory retrieval.

\section{Statistical Analysis}

Place preference was indexed by percentage of time spent in the drug-associated compartment (time spent in the drugassociated compartment $\times 100 /$ total test time). Expression of CPP (CPA in Experiment 4) was confirmed by paired $t$-test comparing preference in the Baseline (pre-conditioning) and Place Preference Test 1 (post-conditioning). Place preference data after counterconditioning ( $\mathrm{LiCl}$ treatment in Experiment 2) were analyzed by a mixed-model ANOVA, with a between-subject factor of Group (Retrieval, No Retrieval) and a repeated measures factor of Test (Place Preference Test 2, Reinstatement Test(s)). ANOVA was followed by Student-Newman-Keuls test where indicated. Data from mice that did not show place preference/aversion in Place Preference Test 1 were excluded from the analysis (One mouse in Experiment 1a, two mice in Experiments 2 and 3a; three mice in Experiments $3 b$ and 4 ).

\section{RESULTS}

Experiments 1a and 1b: Aversive Counterconditioning During Memory Reconsolidation Leads to a LongLasting Prevention of Relapse to Cocaine Seeking

Experiment 1a. First, we assessed the capacity of counterconditioning given after retrieval of cocaine-associated memories (ie, during reconsolidation) to prevent relapse to cocaine seeking, using the CPP paradigm. This paradigm has been widely used to assess the rewarding properties of drugs (Mucha et al, 1982; Itzhak and Martin, 2002; Cunningham et al, 2006), and to model cue-induced craving and relapse through reinstatement of cocaine-CPP (Mueller and Stewart, 2000; Itzhak and Martin, 2002). Our modified place conditioning procedure consisted of two training phases: a cocaine place conditioning phase followed by an aversive place counterconditioning phase with $\mathrm{LiCl}$, which is commonly used to induce CPA (Martin and Itzhak, 2000; Parker and Mcdonald, 2000). For more details, see Materials and Methods.

As presented in Figure 1a (experimental timeline), following a Baseline Test, all mice were first trained in a cocaineCPP procedure. On the next day place preference was tested, and as expected, mice displayed CPP, as reflected by an increased percentage of time spent in the cocaine-paired compartment after place conditioning, compared with baseline (Figures $1 \mathrm{~b} ; t(14)=6.67 ; p<0.0001$ ). In the second phase, mice underwent place counterconditioning with $\mathrm{LiCl}, 1 \mathrm{~h}$ after memory retrieval (Retrieval $1 \mathrm{~h}$ group) or handling (control, No Retrieval group). The 1-h interval was chosen in order for the counterconditioning to be held within the 'reconsolidation window' (Nader and Hardt, 2009; Sartor and Aston-Jones, 2014; Xue et al, 2012). We found in a second place preference test that concluded the counterconditioning phase, that aversive counterconditioning led to the loss of place preference in both groups (Figure $1 \mathrm{~b}$ ). In addition, cocaine and $\mathrm{LiCl}$ administration enhanced and suppressed locomotor activity, respectively (Supplementary Figure S2).

We then tested whether cocaine-CPP will be reinstated by a prime administration of cocaine $(7.5 \mathrm{mg} / \mathrm{kg})$, a wellestablished measure of relapse to cocaine seeking (Mueller and Stewart, 2000). We found that while the No Retrieval group showed reinstatement of cocaine-CPP, the Retrieval $1 \mathrm{~h}$ group did not reinstate the preference to the drug-paired compartment. These results indicate that aversive counterconditioning applied after a cocaine memory retrieval prevents the reinstatement of cocaine seeking (a mixed model ANOVA: a main effect of Test $(\mathrm{F}(1,13)=6.63, p<0.05)$ and a Group $\times$ Test interaction $(\mathrm{F}(1,13)=5.09, p<0.05)$, but no main effect of Group $(p>0.05)$. Post hoc analysis: No Retrieval group: Reinstatement $v$ Place Preference Test 2: $p<0.005$; No Retrieval vs Retrieval $1 \mathrm{~h}$ groups in the Reinstatement Test: $p<0.05)$.

Experiment $1 b$. Next, we assessed whether the prevention of relapse to cocaine seeking by aversive counterconditioning performed within the 'reconsolidation window' is long lasting. As shown in Figure $1 \mathrm{c}$ and d, following the cocaine place conditioning phase mice expressed cocaine-CPP $(t(12)=8.22 ; p<0.0001)$, which was abolished by LiClplace counterconditioning, in both the Retrieval $1 \mathrm{~h}$ and 
No Retrieval groups. To assess the long-lasting effects of counterconditioning conducted within the memory 'reconsolidation window', we tested for reinstatement 14 and 28 days after the last counterconditioning session. In both tests, we found that cocaine-CPP was reinstated in the control, No Retrieval group, but not in the group that underwent memory retrieval prior counterconditioning. These results indicate that the relapse prevention effect produced by counterconditioning within the 'reconsolidation window' is very long lasting (a mixed model $2 \times(3)$ ANOVA: a main effect of Group $(\mathrm{F}(1,11)=5.58, p<0.05)$ and Test $(\mathrm{F}(2,22)=8.57, p<0.005)$, and a Group $\times$ Test interaction $(\mathrm{F}(2,22)=6.73, p<0.01)$. Post hoc analysis: No Retrieval group: Reinstatement 14 or 28 days $v s$ Place Preference Test 2: $p$ 's $<0.005$; No Retrieval vs Retrieval $1 \mathrm{~h}$ groups in the Reinstatement 14 or 28 days tests: p's $<0.05)$.

\section{Experiment 2: Administration of $\mathrm{LiCl}$ within the 'Reconsolidation Window' in the Absence of Counterconditioning Fails to Prevent Relapse to Cocaine Seeking}

We next sought to verify that the effects we observed in Experiment 1 were indeed due to the behavioral effects of LiCl-counterconditioning and not a result of the pharmacological effects of $\mathrm{LiCl}$ per se. Therefore, we tested whether CPP and its reinstatement would be affected by the mere administration of $\mathrm{LiCl}$.

As presented in Figure 2, cocaine-CPP was established as described above, as mice spent more time in the cocainepaired compartment following cocaine place conditioning $(t(18)=8.57 ; p<0.0001)$. Next, mice underwent memory retrieval every other day as described above (Retrieval group), while the No Retrieval controls were briefly handled. An hour later, all mice were administered with $\mathrm{LiCl}$ (vehicle on alternate days) and immediately returned to the home cages (Figure 2a, timeline). We found that following this stage, cocaine place preference was reduced in the group that underwent memory retrieval prior to $\mathrm{LiCl}$ administration $(t(9)=3.82 ; p<0.005)$. However, $24 \mathrm{~h}$ later, both groups exhibited cocaine-CPP after a cocaine prime administration, indicating that $\mathrm{LiCl}$ administration per se, given after memory retrieval, does not prevent relapse to cocaine CPP. These findings suggest that $\mathrm{LiCl}$ on its own does not disrupt memory reconsolidation (a mixed-model ANOVA: a main effect of Test $(\mathrm{F}(1,17)=5.77, p<0.05)$, but no significant main effect of Group and no interaction, p's >0.05).

Our results raised the possibility that $\mathrm{LiCl}$ given $1 \mathrm{~h}$ after a brief memory retrieval disrupted the expression (but not the reinstatement) of cocaine-CPP. Therefore, we next tested whether $\mathrm{LiCl}$ can produce trace place conditioning, namely, that the presentation of the unconditioned stimulus (US; $\mathrm{LiCl}$ ) $1 \mathrm{~h}$ after the 4-min exposure to the conditioned stimulus (CS, paired-compartment) would lead to CPA. As depicted in Supplementary Figure S3, mice did not show preference to either compartments, ruling out the possibility that the absence of CPP expression in the Retrieval group in Experiment 2 was due to trace conditioning.
Experiments 3a and 3b: Aversive Counterconditioning Applied Outside the 'Reconsolidation Window' Fails to Prevent Relapse to Cocaine Seeking

Experiment 3a. According to the memory reconsolidation hypothesis, the 'reconsolidation window', during which memories are labile for manipulations, lasts 5-6h (Nader and Hardt, 2009; Barak et al, 2013). Therefore, applying a manipulation aimed at disrupting memory reconsolidation after the 'reconsolidation window' closes would not affect the target memory and its behavioral expression (Nader and Hardt, 2009; Milton and Everitt, 2012). Thus, we tested whether aversive counterconditioning conducted outside the 'reconsolidation window', that is, $5 \mathrm{~h}$ after the retrieval of cocaine-associated memories (Barak et al, 2013), would fail to reinstate cocaine-seeking behavior.

As shown in Figure $3 a$ and $b$, mice first went through cocaine place conditioning and displayed cocaine-CPP $(t(14)=8.38 ; p<0.0001)$. Next, mice received either a brief memory retrieval (Retrieval $5 \mathrm{~h}$ group) or were handled (control, No Retrieval group) as described above, and were then returned for $5 \mathrm{~h}$ to their home cage before receiving the LiCl-counterconditioning. Following the aversive training, CPP was abolished in both groups (Figure $3 b$ ). However, the next day we found that both groups showed reinstatement of cocaine-CPP, indicating that aversive counterconditioning applied after the closure of the 'reconsolidation window' fails to block relapse to cocaine-seeking behavior (a mixed-model ANOVA: a main effect of Test $(\mathrm{F}(1,13)=21.22, p<0.0005)$, but no significant main effect of Group and no interaction, p’s >0.05).

Experiment 3b. Retrieval (reactivation) of the memory is postulated to be the initiating first step of the memory destabilization-reconsolidation process (Nader and Hardt, 2009; Everitt, 2014). Thus, the memory must be retrieved to open the 'reconsolidation window', prior to any memory attenuating manipulation. However, there is evidence that a reversed protocol, in which the memory is retrieved shortly after extinction training, may also attenuate the memories and prevent the reinstatement of the target behavior (Baker et al, 2013; Millan et al, 2013). Therefore, we tested whether aversive counterconditioning followed (rather than preceded) by memory retrieval would affect the reinstatement of cocaine-seeking behavior.

As depicted in Figure $3 \mathrm{c}$ and similar to the experiments above, mice were first trained in a cocaine place conditioning procedure and displayed CPP $(t(17)=6.40 ; p<0.0001)$. Next, mice first underwent LiCl-place counterconditioning, and $1 \mathrm{~h}$ later were either briefly exposed to the paired compartment as described above ( $1 \mathrm{~h}$ Retrieval group) or were handled (No Retrieval group). As in the experiments above, aversive counterconditioning abolished cocaine-CPP in both groups (Figure $3 \mathrm{~d}$ ). However, a prime injection of cocaine $24 \mathrm{~h}$ later reinstated cocaine-CPP in both groups (a mixedmodel ANOVA: a main effect of Test $(\mathrm{F}(1,16)=14.81$, $p<0.005)$, but no significant main effect of Group and no interaction, $p$ 's $>0.05$ ).

Taken together, results from Experiments $3 \mathrm{a}$ and $3 \mathrm{~b}$ indicate that counterconditioning applied outside the 'reconsolidation window' (ie, before or long after memory retrieval) cannot prevent the reinstatement of cocaine 


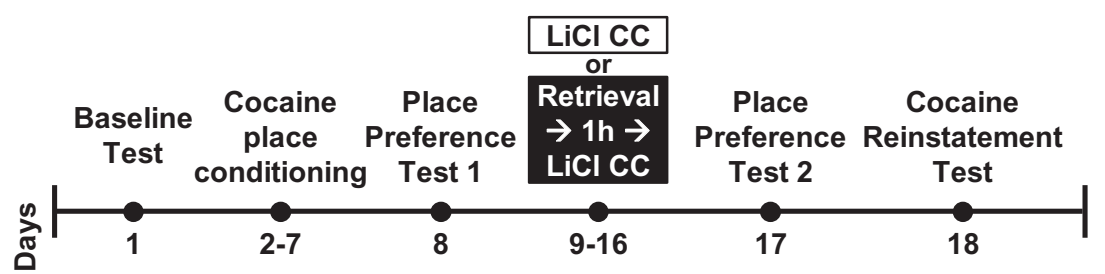

b

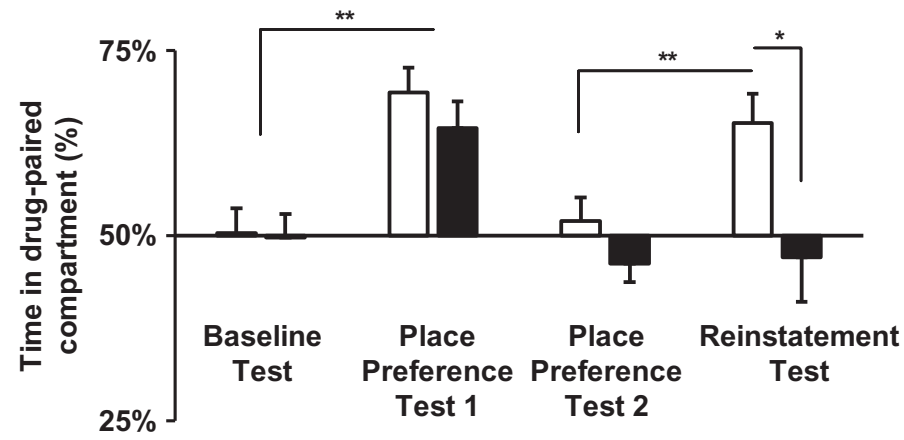

口 No Retrieval $\quad$ Retrieval $1 \mathrm{~h}$
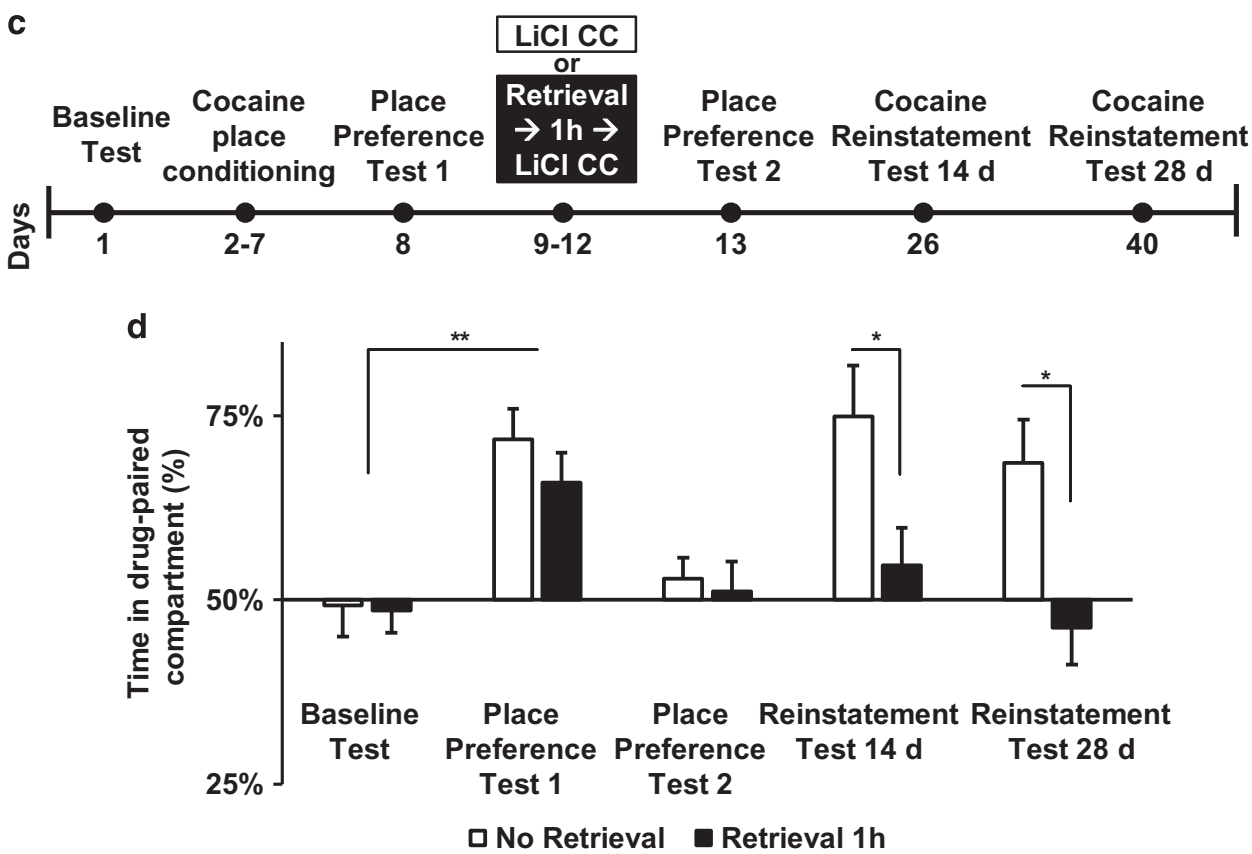

Figure I (a, b) Aversive counterconditioning conducted I h after retrieval of cocaine-associated memories prevents reinstatement of cocaine-conditioned place preference. (a) Schematic representation of the experimental procedure ( $\mathrm{LiCl}$, lithium chloride; CC, counterconditioning). Mice were first trained in a cocaine $(15 \mathrm{mg} / \mathrm{kg}$ ) conditioned place preference (CPP) procedure, and then received place counterconditioning with LiCl (I50 mg/kg), conducted I h after a memory retrieval session consisting of a 4-min re-exposure to the drug-associated compartment (Retrieval I h group), or handling (control, No Retrieval group). Place preference tests were conducted after completion of the place conditioning and counterconditioning stages. Reinstatement of cocaine-CPP was tested $24 \mathrm{~h}$ after validation of CPP loss, following administration of a $7.5 \mathrm{mg} / \mathrm{kg}$ cocaine prime. (b) Place preference/aversion scores, expressed as mean+SEM of the percent of time spent in the cocaine/LiCl-paired compartment; $* p<0.05 ; * * 2 p<0.01 ; n=7-8$ per group. (c, d) Aversive counterconditioning conducted I h after retrieval of cocaine-associated memories induces long-lasting prevention of the reinstatement of cocaine-conditioned place preference. (c) Mice were first trained in a cocaine CPP procedure, and then received place counterconditioning with LiCl, conducted I h after a memory retrieval session (Retrieval I h group), or handling (control, No Retrieval group). Place preference tests were conducted after completion of the place conditioning and counterconditioning stages. Reinstatement of cocaine-CPP was assessed 14 and 28 days after the last counterconditioning session following administration of a cocaine prime. (d) Place preference/aversion scores, expressed as mean+SEM of the percent of time spent in the cocaine/ $\mathrm{LiCl}$-paired compartment; ${ }^{*} p<0.05 ;$ ** $p<0.01 ; n=6-7$ per group. 

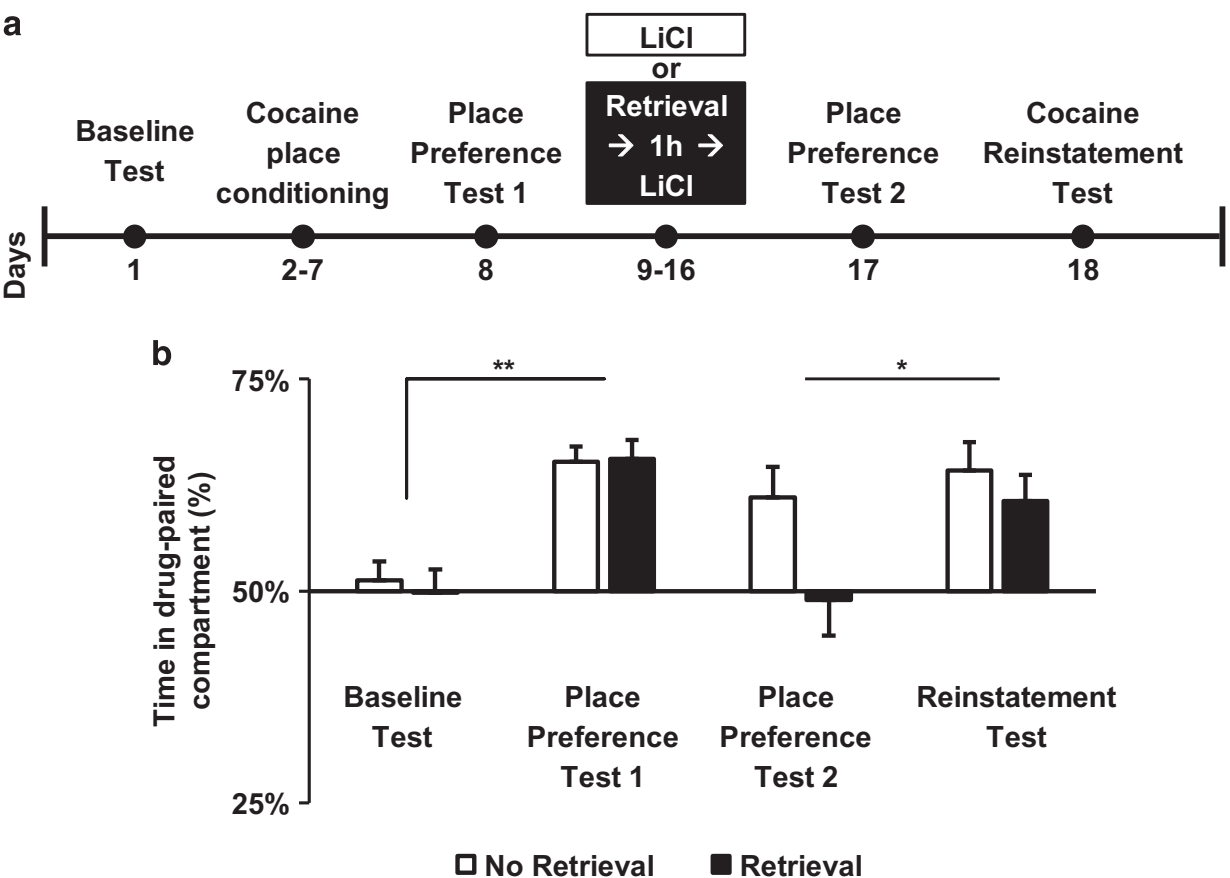

Figure 2 Administration of $\mathrm{LiCl}$ I h after retrieval of cocaine-associated memories without counterconditioning training does not prevent reinstatement of cocaine-conditioned place preference. (a) Experimental design and timeline ( $\mathrm{LiCl}$, lithium chloride; CC, counterconditioning). Mice were first trained in a cocaine ( $15 \mathrm{mg} / \mathrm{kg}$ ) conditioned place preference (CPP) procedure, and then place preference was tested. In the next stage, mice from the Retrieval group received a 4-min re-exposure to the drug-associated compartment (memory retrieval), and after I h were administered with LiCl (I $50 \mathrm{mg} / \mathrm{kg}$ ), and returned to their home cages. No Retrieval controls received the $\mathrm{LiCl}$ treatment I h after brief handling. A second place preference test was conducted after the completion of this stage. Reinstatement of cocaine-CPP was tested following administration of a $7.5 \mathrm{mg} / \mathrm{kg}$ cocaine prime. (b) Place preference/aversion scores, expressed as mean+SEM of the percent of time spent in the cocaine/LiCl-paired compartment; $* p<0.05 ; * * p<0.01 ; n=9-10$ per group.

seeking, implying that the context-cocaine memory remained intact, and was later recovered.

\section{Experiment 4: Appetitive Counterconditioning Applied within the 'Reconsolidation Window' Prevents the Reinstatement of Place Aversion}

Next, we sought to show that the effect of post-retrieval counterconditioning does not depend on the nature of motivational reinforcements. More specifically, in the experiments above we first trained mice with an appetitive place conditioning (cocaine), and then counterconditioned the same place with an aversive outcome, within or outside the 'reconsolidation window'. Here, we determined whether reconsolidation of aversive memories could be disrupted by appetitive counterconditioning. For this end we first trained the mice to avoid one of the compartments with a LiCl-CPA procedure (eg, Martin and Itzhak, 2000; Parker and Mcdonald, 2000; Legastelois et al, 2015), and then tested if counterconditioning by appetitive cocaine-CPP, with or without a prior memory retrieval, can abolish the relapse of avoidance behavior. Thus, the experiment was performed to provide a proof of concept for the post-retrieval counterconditioning paradigm, and was designed in a reversed order compared with the experiments above.

As expected, we found that following $\mathrm{LiCl}$ place conditioning, the percentage of time spent in the paired compartment significantly decreased compared with baseline (Figure 4; $(t(13)=5.62 ; p<0.0001))$, indicating expression of CPA. In the second phase, mice underwent place counterconditioning with cocaine $1 \mathrm{~h}$ after memory retrieval (Retrieval group) or handling (control, No Retrieval group). We found that following cocaine place counterconditioning, both groups showed preference for the drug-paired compartment, suggesting that appetitive counterconditioning effectively abolished LiCl-CPA and produced cocaine-CPP. We then tested whether administration of a prime dose of $\mathrm{LiCl}$ would lead to the reinstatement of place aversion. We found that in control mice, which received cocaine-counterconditioning without prior retrieval, $\mathrm{LiCl}$ prime led to the loss of preference for the drug-paired compartment, suggesting a partial reinstatement of CPA (Figure 4b). However, mice that received the cocaine-counterconditioning training after memory retrieval (ie, during memory reconsolidation) persisted in showing preference for the drug-paired compartment. This finding indicates that conducting appetitive counterconditioning within the 'reconsolidation window' prevents relapse of the aversive memory (a mixed-model ANOVA: a Group $\times$ Test interaction $(\mathrm{F}(1,12)=7.82, p<0.02)$; no significant main effects ( $p$ 's $>0.05)$. Post hoc analysis: No Retrieval: Reinstatement vs Place preference Test 2: $p<0.01$; No Retrieval vs Retrieval $1 \mathrm{~h}$ groups in the Reinstatement Test: $p<0.05$ ).

Taken together, these results show that retrieval of the memory before a counterconditioning session can prevent the relapse of the original memory, regardless of the motivational properties of the memory (appetitive or aversive). 


\section{a}

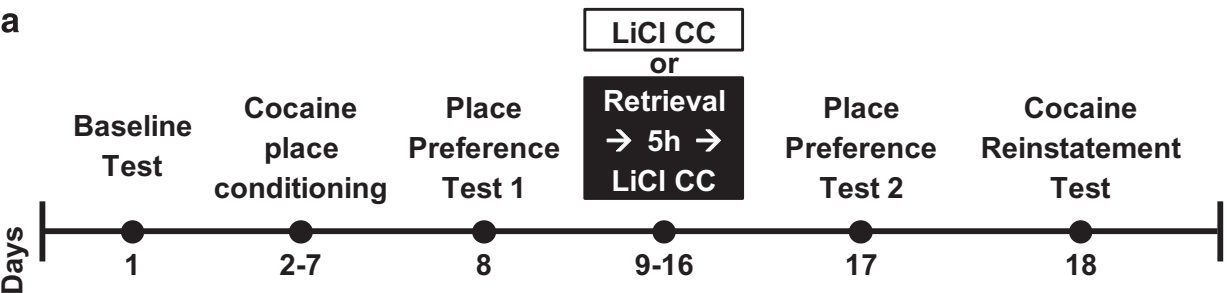

b

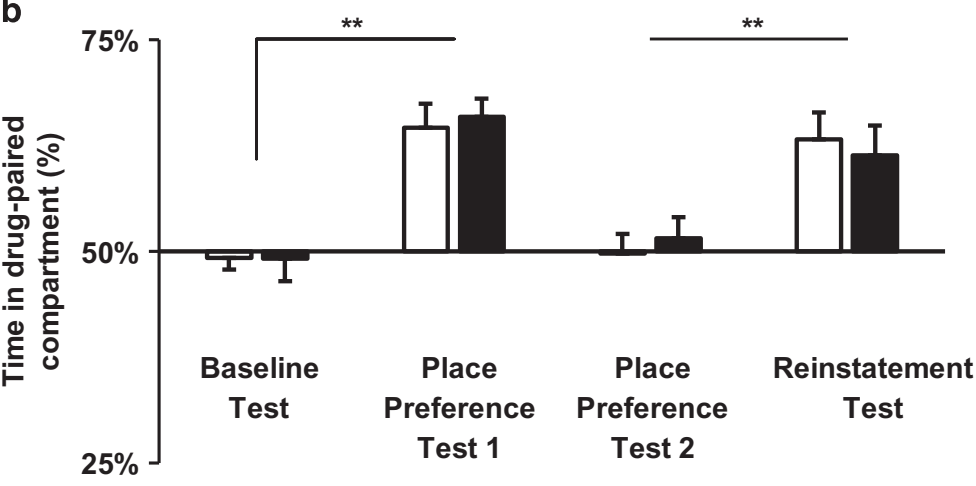

$\square$ No Retrieval $\square$ Retrieval $5 \mathrm{~h}$

C
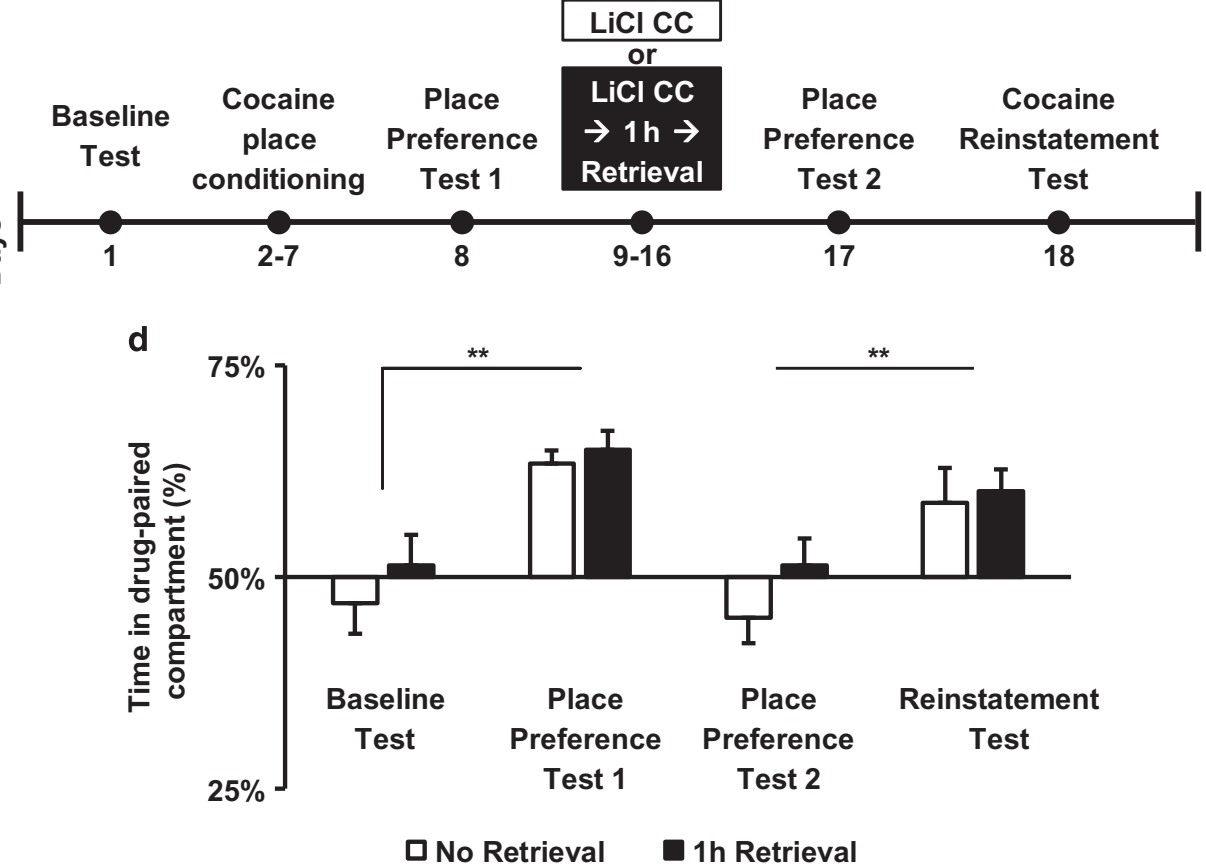

Figure 3 Aversive counterconditioning applied outside the 'reconsolidation window' does not prevent reinstatement of cocaine-conditioned place preference. (a, b) Aversive counterconditioning conducted $5 \mathrm{~h}$ after retrieval of cocaine-associated memories. (a) Experimental design and timeline (LiCl, lithium chloride; CC, counterconditioning). Mice were first trained in a cocaine ( $15 \mathrm{mg} / \mathrm{kg}$ ) conditioned place preference (CPP) procedure, and then received place counterconditioning with $\mathrm{LiCl}(150 \mathrm{mg} / \mathrm{kg}$ ), conducted $5 \mathrm{~h}$ after a memory retrieval session consisting of a 4-min re-exposure to the drug-associated compartment (Retrieval $5 \mathrm{~h}$ group) or handling (control, No Retrieval group). Place preference tests were conducted after completion of the CPP and counterconditioning stages. Reinstatement of cocaine-CPP was tested following administration of a $7.5 \mathrm{mg} / \mathrm{kg}$ cocaine prime. (b) Place preference/aversion scores, expressed as mean+SEM of the percent of time spent in the cocaine/LiCl-paired compartment; *** $<0.0$ I; $n=7-8$ per group. (c, d). Aversive counterconditioning conducted I h prior to cocaine-associated memory retrieval. (c) Experimental design and timeline. Mice were first trained in a cocaine ( I $5 \mathrm{mg} / \mathrm{kg}$ ) CPP procedure, and then received place counterconditioning with $\mathrm{LiCl}(\mathrm{I} 5 \mathrm{mg} / \mathrm{kg})$. After I h, mice from the I h Retrieval group received a 4-min re-exposure to the drug-associated compartment (memory retrieval). Control group (No Retrieval) was handled. (d) Place preference/aversion scores, expressed as mean+SEM of the percent of time spent in the cocaine/LiCl-paired compartment; $* * *<0.01 ; n=9$ per group. 

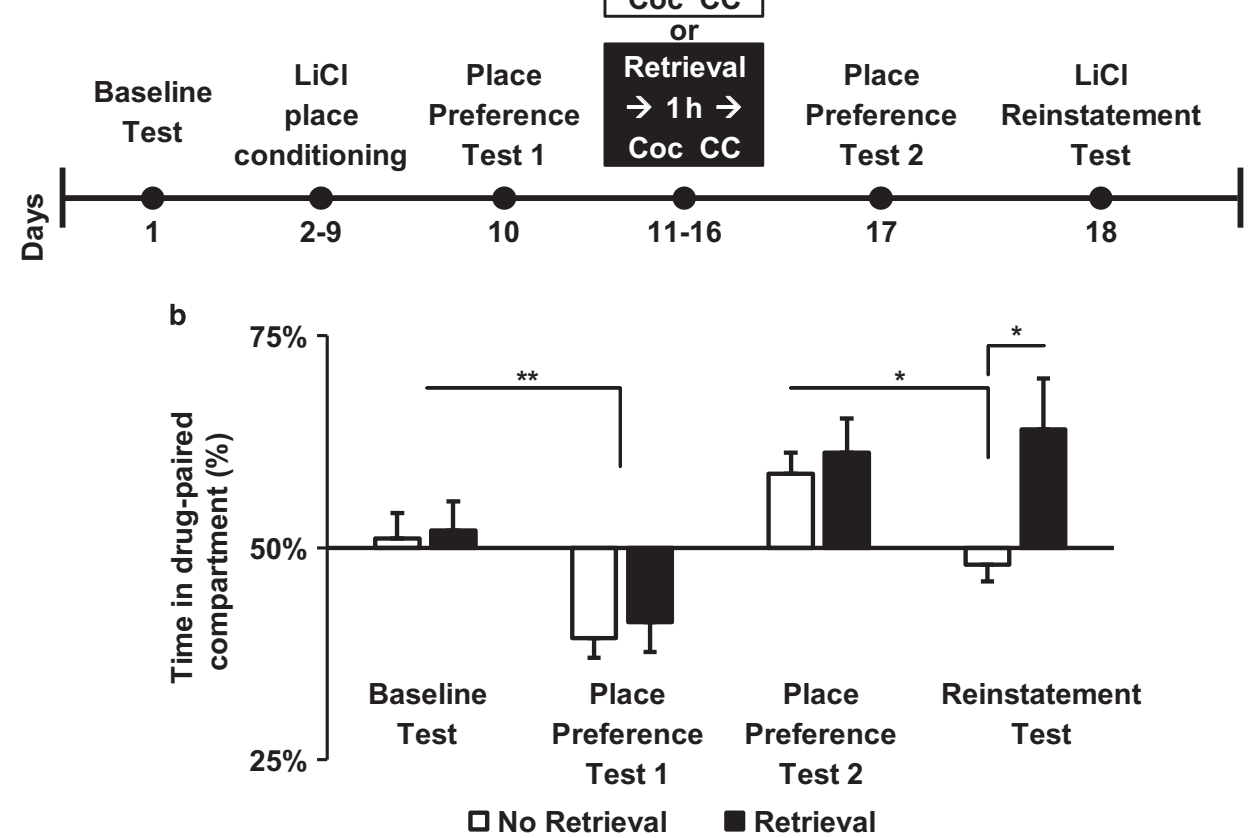

Figure 4 Appetitive counterconditioning conducted I h after retrieval of aversive LiCl-associated memories prevents reinstatement of place avoidance behavior. (a) Experimental design and timeline ( $\mathrm{LiCl}$, lithium chloride; Coc, cocaine; CC, counterconditioning). Mice were first trained in a LiCl (I50 mg/kg) conditioned place aversion (CPA) procedure, and then received place counterconditioning with cocaine ( I5 mg/kg), conducted I h after a memory retrieval session consisting of a 4-min re-exposure to the drug-associated compartment (Retrieval I h group) or after handling (control, No Retrieval group). Place preference tests were conducted after completion of the CPA and counterconditioning stages. Reinstatement of LiCl-CPA was tested following administration of a $75 \mathrm{mg} / \mathrm{kg} \mathrm{LiCl}$ prime. (b) Place preference/aversion scores expressed as mean+SEM of the percent of time spent in the LiCl/cocaine-paired compartment; $* p<0.05$; ** $p<0.0$ I $n=7$ per group.

\section{DISCUSSION}

Here, we developed a novel memory replacement procedure, indicating that aversive counterconditioning conducted $1 \mathrm{~h}$ after a brief retrieval of cocaine-associated memories produces a long-lasting prevention of the reinstatement of cocaine-seeking behavior in a CPP paradigm. Our findings suggest that under such conditions the recovery of the cuecocaine memory is prevented, possibly due to replacement by a cue-aversion memory (Figure 5). Importantly, aversive counterconditioning prevents relapse only when conducted shortly after retrieval (during reconsolidation), but not when conducted before or long after retrieval (outside the 'reconsolidation window'). Furthermore, we also show that aversive, LiCl-associated memories can be countered by cocaine memories via post-retrieval appetitive counterconditioning, which prevents relapse of avoidance behavior. Thus, our findings indicate that the memory replacement procedure introduced here can be applied to replace appetitive with aversive memories and vice versa, and can be used to change unwanted maladaptive behaviors into desirable, adaptive behaviors.

Recently, it has been demonstrated in several addictionrelated procedures that conducting extinction training following a brief memory retrieval session prevents relapse to drugs seeking (Luo et al, 2015; Ma et al, 2012; Millan et al, 2013; Sartor and Aston-Jones, 2014; Xue et al, 2012). Based on previous similar studies in fear conditioning procedures (eg, Liu et al, 2014; Monfils et al, 2009), it has been postulated that extinction training performed within the 'reconsolidation window' leads to incorporation of the new information (cue-nothing association) into the original cuereinforcement memory trace (eg, cue-drug) (Millan et al, 2013; Monfils et al, 2009; Sartor and Aston-Jones, 2014; Xue et al, 2012), rather than creating a competing memory as in regular extinction (Bouton, 2002; Milton and Everitt, 2012). However, several studies on fear memories showed that postretrieval extinction did not always prevent reinstatement of fear behavior (Chan et al, 2010; Costanzi et al, 2011; Ishii et al, 2015; Soeter and Kindt, 2011), and studies on drug relapse showed attenuation, but not always prevention of relapse to drug seeking (Luo et al, 2015; Xue et al, 2012). Comparative studies have indicated that counterconditioning may have a stronger suppressive effect on relapse of memories, compared with extinction (Tunstall et al, 2012; Van Gucht et al, 2010). Yet, similar to extinction, this relapse suppressing effect is temporary, and reinstatement of the target memories often occurs (Bouton and Peck, 1992; Brooks et al, 1995; Tunstall et al, 2012). Here, we suggest that conducting counterconditioning during memory reconsolidation may provide a very potent approach of behavioral intervention aimed at preventing the recovery of drug memories. Moreover, our findings support the possibility that rather than forming a new memory trace as in the regular counterconditioning procedure, counterconditioning administered during reconsolidation led to incorporation of the aversive information into the original memory trace, so that the retrieved cue-cocaine memory was reconsolidated as a cue-aversion memory, and therefore the reinstatement of cocaine-seeking behavior was prevented. Nonetheless, the notion that the memory was replaced is yet to be shown 
directly in the future using ensemble/engram procedures (Cruz et al, 2013; Pfarr et al, 2015).

Interestingly, several studies have recently shown that flipping the order of events in the retrieval-extinction procedure, that is, retrieving the memory after, rather than before extinction training, can prevent relapse in a similar manner to post-retrieval extinction (Baker et al, 2013; Millan et al, 2013), suggesting that the mechanisms underlying this procedure are not necessarily reconsolidation mechanisms. In the present study, however, flipping the order of the events, by retrieving the memory after, rather than before the counterconditioning training, did not block the reinstatement of cocaine seeking (Experiment $3 \mathrm{~b}$ ), further supporting our notion that the results we observed are mediated by memory reconsolidation mechanisms.

We found that $\mathrm{LiCl}$ on its own does not disrupt memory reconsolidation, and that counterconditioning training is required to prevent reinstatement of cocaine-CPP. Interestingly, it was recently shown that administration of $\mathrm{LiCl}$ immediately after memory retrieval abolished the expression of cocaine-CPP (Wu et al, 2011). The authors suggested that $\mathrm{LiCl}$ disrupted the reconsolidation of cocaine-associated memories via its pharmacological properties, namely, inhibition of glycogen synthase kinase $3 \beta$ (GSK3 3$)$ (Wu et al, 2011), which is implicated in synaptic plasticity, learning, and memory formation (Dewachter et al, 2009). However, we show here that the mere administration of $\mathrm{LiCl}$ after memory retrieval without a counterconditioning indeed decreases the expression of cocaine-CPP, but it does not prevent the reinstatement of CPP triggered by a cocaine prime (Experiment 2), implying that memory reconsolidation is not affected by LiCl per se in the absence of the behavioral, aversive counterconditioning. Thus, our results suggest that the pharmacological effects of $\mathrm{LiCl}$, for example, GSK3 $\beta$ inhibition, can potentially facilitate extinction (see Echeverria and Iarkov, 2014), yet are insufficient to disrupt the reconsolidation of cocaine-associated memories and to prevent relapse. Therefore, the long-lasting prevention of relapse observed in our study is likely due to the behavioral training, that is, re-associating the cues with LiCl-induced malaise during memory reconsolidation.

Mice developed place aversion to a compartment paired with the administration of $150 \mathrm{mg} / \mathrm{kg} \mathrm{LiCl}$ (Experiment 4), in line with previous findings (Martin and Itzhak, 2000). Interestingly, in this experiment we observed an inversion in the conditioned response, whereby the mice, which showed LiCl-CPA after the first conditioning phase, showed cocaine-CPP following the second, counterconditioning phase. Notably, in the experiments where mice were first trained to show cocaine CPP, counterconditioning with $\mathrm{LiCl}$ led to the abolition of cocaine-induced place preference, yet no place aversion was displayed, that is, mice showed no preference to either compartments. We assume that the strong reinforcing properties of cocaine countered the aversive effects of $\mathrm{LiCl}$ with higher efficacy than vice versa. This strong counterconditioning effect of cocaine was also reflected in the reinstatement phase of Experiment 4, in which a $\mathrm{LiCl}$ prime led to the loss of place preference but not to place aversion in controls (No Retrieval group), probably due to a remnant effect of the strong cocaine place (counter) conditioning. It is plausible, however, that a stronger $\mathrm{LiCl}-$

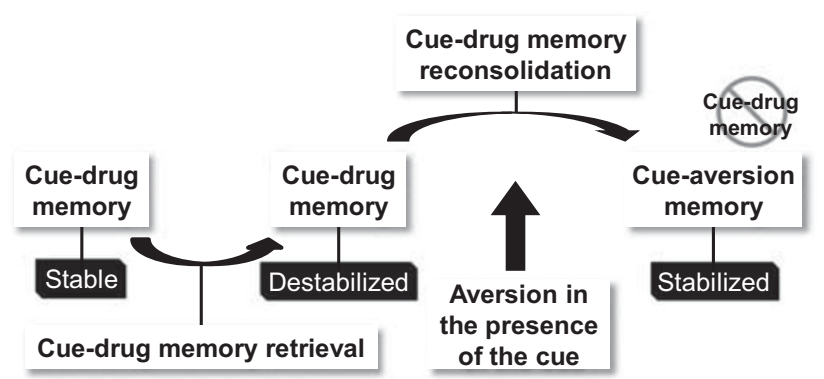

Figure 5 A model illustrating the memory replacement paradigm. A cuedrug memory is destabilized upon retrieval by exposure to the cue, and subsequently enters the reconsolidation phase. Pairing of the cue with an aversive consequence within the 'reconsolidation window' leads to incorporation of aversive information into the original memory trace, so that the retrieved cue-drug memory is reconsolidated as a cue-aversion memory; therefore, the cue ceases to evoke craving and relapse.

counterconditioning (eg, with higher doses of $\mathrm{LiCl}$ or additional/longer counterconditioning sessions) would have led to the explicit expression of place aversion.

After establishing the capacity of the post-retrieval counterconditioning procedure to counter, or replace the appetitive with an aversive memory, we also demonstrate that an aversive memory, as manifested by LiCl-CPA, can be replaced with a new appetitive memory of a cue-cocaine association, via appetitive counterconditioning during the 'reconsolidation window' (Experiment 4). Thus, our results indicate that via counterconditioning during reconsolidation, it is possible to change an appetitive memory into an aversive memory and vice versa. In other words, the paradigm is effective regardless of the direction of change in motivational or affective valence. Maladaptive associative memories are involved in the pathology of several psychiatric disorders besides addiction, such as phobias (Mineka and Ohman, 2002), post-traumatic stress disorder (Desmedt et al, 2015), and obsessive-compulsive disorder (Gillan et al, 2011). Therefore, utilizing the retrieval-counterconditioning procedure to replace these unwanted memories with adaptive memories is a potentially novel behavioral therapeutic approach for these neuropsychiatric disorders. Indeed, Das et al (2015) recently demonstrated that human hazardous drinkers expressed less attention bias towards alcohol-related stimuli after exposure to aversive taste or pictures during reconsolidation, further pointing to the translational value of the present approach to reduce cue-induced craving and relapse in drug addicts.

Taken together, our findings indicate that the novel postretrieval counterconditioning paradigm presented here is a promising behavioral approach for replacing maladaptive, unwanted memories with adaptive ones, by shifting the emotional valence of the conditioned stimulus during reconsolidation. In particular, our findings hold promise for prevention of relapse to drug abuse by countering the valence of the drug paraphernalia. As such, the paradigm provides a novel potential therapeutic approach based on behavioral training and without pharmacological side effects, and can be applied to a range of psychiatric disorders involving maladaptive, pathogenic memories. 


\section{FUNDING AND DISCLOSURE}

The research was supported by funds from the Israel Science Foundation grants 968-13 and 1916-13 (to SB) and the German Israeli Foundation grant I-2348-105.4/2014 (to SB). The authors declare no conflict of interest.

\section{ACKNOWLEDGMENTS}

$\mathrm{KG}, \mathrm{LB}$, and SB designed the research and analyzed data; KG and LB performed the research; and $\mathrm{KG}$ and $\mathrm{SB}$ wrote the paper. We thank Hadas Laufer, Yossi Sadot, Adaya Turkia, and other laboratory members for fruitful discussion and comments on this manuscript.

\section{REFERENCES}

Baker KD, McNally GP, Richardson R (2013). Memory retrieval before or after extinction reduces recovery of fear in adolescent rats. Learn Mem 20: 467-473.

Barak S, Liu F, Ben Hamida S, Yowell QV, Neasta J, Kharazia V et al (2013). Disruption of alcohol-related memories by mTORC1 inhibition prevents relapse. Nat Neurosci 16: 1111-1117.

Bouton ME (2002). Context, ambiguity, and unlearning: sources of relapse after behavioral extinction. Biol Psychiatry 52: 976-986.

Bouton ME, Peck CA (1992). Spontaneous-recovery in crossmotivational transfer (counterconditioning). Anim Learn Behav 20: 313-321.

Brooks DC, Hale B, Nelson JB, Bouton ME (1995). Reinstatement after counterconditioning. Anim Learn Behav 23: 383-390.

Cannon DS, Baker TB, Wehl CK (1981). Emetic and electric shock alcohol aversion therapy: six- and twelve-month follow-up. J Consult Clin Psychol 49: 360-368.

Chan WY, Leung HT, Westbrook RF, McNally GP (2010). Effects of recent exposure to a conditioned stimulus on extinction of Pavlovian fear conditioning. Learn Mem 17: 512-521.

Costanzi M, Cannas S, Saraulli D, Rossi-Arnaud C, Cestari V (2011). Extinction after retrieval: effects on the associative and nonassociative components of remote contextual fear memory. Learn Mem 18: 508-518.

Cruz FC, Koya E, Guez-Barber DH, Bossert JM, Lupica CR, Shaham Y et al (2013). New technologies for examining the role of neuronal ensembles in drug addiction and fear. Nat Rev Neurosci 14: 743-754.

Cunningham CL, Gremel CM, Groblewski PA (2006). Druginduced conditioned place preference and aversion in mice. Nat Protoc 1: 1662-1670.

Das RK, Lawn W, Kamboj SK (2015). Rewriting the valuation and salience of alcohol-related stimuli via memory reconsolidation. Transl psychiatry 5: e645.

Desmedt A, Marighetto A, Piazza PV (2015). Abnormal fear memory as a model for posttraumatic stress disorder. Biol Psychiatry 78: 290-297.

Dewachter I, Ris L, Jaworski T, Seymour CM, Kremer A, Borghgraef P et al (2009). GSK3beta, a centre-staged kinase in neuropsychiatric disorders, modulates long term memory by inhibitory phosphorylation at serine-9. Neurobiol Dis 35: 193-200.

Dudai Y (2012). The restless engram: consolidations never end. Ann Rev Neurosci 35: 227-247.

Echeverria V, Iarkov A (2014). Potential mechanisms underlying the facilitation of fear memory extinction by cotinine. $\mathrm{Br} J \mathrm{Med}$ Med Res 4: 632-648.

Everitt BJ (2014). Neural and psychological mechanisms underlying compulsive drug seeking habits and drug memories-indications for novel treatments of addiction. Eur J Neurosci 40: 2163-2182.
Frawley PJ, Smith JW (1990). Chemical aversion therapy in the treatment of cocaine dependence as part of a multimodal treatment program: treatment outcome. J Subst AbuseTreat 7: 21-29.

Gillan CM, Papmeyer M, Morein-Zamir S, Sahakian BJ, Fineberg NA, Robbins TW et al (2011). Disruption in the balance between goal-directed behavior and habit learning in obsessivecompulsive disorder. Am J Psychiatry 168: 718-726.

Hyman SE (2005). Addiction: a disease of learning and memory. Am J Psychiatry 162: 1414-1422.

Hyman SE, Malenka RC, Nestler EJ (2006). Neural mechanisms of addiction: the role of reward-related learning and memory. Ann Rev Neurosci 29: 565-598.

Ishii D, Matsuzawa D, Matsuda S, Tomizawa H, Sutoh C, Shimizu E (2015). An isolated retrieval trial before extinction session does not prevent the return of fear. Behav Brain Res 287: 139-145.

Itzhak Y, Martin JL (2002). Cocaine-induced conditioned place preference in mice: induction, extinction and reinstatement by related psychostimulants. Neuropsychopharmacology 26: 130-134.

Legastelois R, Darcq E, Wegner SA, Lombroso PJ, Ron D (2015). Striatal-enriched protein tyrosine phosphatase controls responses to aversive stimuli: implication for ethanol drinking. PLoS One 10: $\mathrm{e} 0127408$.

Liu J, Zhao L, Xue Y, Shi J, Suo L, Luo Y et al (2014). An unconditioned stimulus retrieval extinction procedure to prevent the return of fear memory. Biol Psychiatry 76: 895-901.

Luo YX, Xue YX, Liu JF, Shi HS, Jian M, Han Y et al (2015). A novel UCS memory retrieval-extinction procedure to inhibit relapse to drug seeking. Nat Commun 6: 7675.

Ma X, Zhang JJ, Yu LC (2012). Post-retrieval extinction training enhances or hinders the extinction of morphine-induced conditioned place preference in rats dependent on the retrievalextinction interval. Psychopharmacology (Berl) 221: 19-26.

Martin JL, Itzhak Y (2000). 7-Nitroindazole blocks nicotine-induced conditioned place preference but not $\mathrm{LiCl}$-induced conditioned place aversion. NeuroReport 11: 947-949.

Merlo E, Milton AL, Everitt BJ (2015). Enhancing cognition by affecting memory reconsolidation. Curr Opin Behav Sci 4: 41-47. Millan EZ, Milligan-Saville J, McNally GP (2013). Memory retrieval, extinction, and reinstatement of alcohol seeking. Neurobiol Learn Mem 101: 26-32.

Milton AL, Everitt BJ (2012). The persistence of maladaptive memory: addiction, drug memories and anti-relapse treatments. Neurosci Biobehav Rev 36: 1119-1139.

Mineka S, Ohman A (2002). Born to fear: non-associative vs associative factors in the etiology of phobias. Behav Res Ther $\mathbf{4 0}$ : 173-184.

Monfils MH, Cowansage KK, Klann E, LeDoux JE (2009). Extinction-reconsolidation boundaries: key to persistent attenuation of fear memories. Science 324: 951-955.

Mucha RF, Vanderkooy D, Oshaughnessy M, Bucenieks P (1982). Drug reinforcement studied by the use of place conditioning in rat. Brain Res 243: 91-105.

Mueller D, Stewart J (2000). Cocaine-induced conditioned place preference: reinstatement by priming injections of cocaine after extinction. Behav Brain Res 115: 39-47.

Nader K, Hardt O (2009). A single standard for memory: the case for reconsolidation. Nat Rev Neurosci 10: 224-234.

O'Brien CP, Childress AR, McLellan AT, Ehrman R (1992). Classical conditioning in drug-dependent humans. Ann NY Acad Sci 654: 400-415.

Parker LA, Mcdonald RV (2000). Reinstatement of both a conditioned place preference and a conditioned place aversion with drug primes. Pharmacol Biochem Behav 66: 559-561.

Pfarr S, Meinhardt MW, Klee ML, Hansson AC, Vengeliene V, Schonig K et al (2015). Losing control: excessive alcohol seeking after selective inactivation of cue-responsive neurons in the infralimbic cortex. J Neurosci 35: 10750-10761. 
Reichelt AC, Lee JL (2013). Memory reconsolidation in aversive and appetitive settings. Front Behav Neurosci 7: 118.

Sartor GC, Aston-Jones G (2014). Post-retrieval extinction attenuates cocaine memories. Neuropsychopharmacology 39: 1059-1065.

Soeter M, Kindt M (2011). Disrupting reconsolidation: pharmacological and behavioral manipulations. Learn Mem 18: 357-366.

Stewart J, de Wit H, Eikelboom R (1984). Role of unconditioned and conditioned drug effects in the self-administration of opiates and stimulants. Psychol Rev 91: 251-268.

Tronson NC, Taylor JR (2013). Addiction: a drug-induced disorder of memory reconsolidation. Curr Opin Neurobiol 23: 573-580.

Tunstall BJ, Verendeev A, Kearns DN (2012). A comparison of therapies for the treatment of drug cues: counterconditioning vs. extinction in male rats. Exp Clin Psychopharmacol 20: 447-453.

Van Gucht D, Baeyens F, Vansteenwegen D, Hermans D, Beckers T (2010). Counterconditioning reduces cue-induced craving and actual cue-elicited consumption. Emotion 10: 688-695. von der Goltz C, Vengeliene V, Bilbao A, Perreau-Lenz S, Pawlak CR, Kiefer F et al (2009). Cue-induced alcohol-seeking behaviour is reduced by disrupting the reconsolidation of alcohol-related memories. Psychopharmacology (Berl) 205: 389-397.

Wikler A (1973). Dynamics of drug dependence. Implications of a conditioning theory for research and treatment. Arch Gen Psychiatry 28: 611-616.

Wise RA (1987). The role of reward pathways in the development of drug dependence. Pharmacol Ther 35: 227-263.

Wu P, Xue YX, Ding ZB, Xue LF, Xu CM, Lu L (2011). Glycogen synthase kinase 3 beta in the basolateral amygdala is critical for the reconsolidation of cocaine reward memory. J Neurochem 118: $113-125$.

Xue YX, Luo YX, Wu P, Shi HS, Xue LF, Chen C et al (2012). A memory retrieval-extinction procedure to prevent drug craving and relapse. Science 336: 241-245.

Supplementary Information accompanies the paper on the Neuropsychopharmacology website (http://www.nature.com/npp) 